\title{
ВM] Global Health Research gaps in the organisation of primary healthcare in low-income and middle-income countries and ways to address them: a mixed-methods approach
}

\author{
Felicity Goodyear-Smith, ${ }^{1}$ Andrew Bazemore, ${ }^{2}$ Megan Coffman, ${ }^{2}$ \\ Richard D W Fortier, ${ }^{\oplus 1,3}$ Amanda Howe, ${ }^{4}$ Michael Kidd, ${ }^{5,6}$ Robert Phillips, ${ }^{7}$ \\ Katherine Rouleau, ${ }^{\odot 5}$ Chris van Weel ${ }^{\otimes 8,9}$
}

To cite: Goodyear-Smith $\mathrm{F}$, Bazemore A, Coffman M, et al. Research gaps in the organisation of primary healthcare in low-income and middle-income countries and ways to address them: a mixed-methods approach. BMJ Global Health 2019;4:e001482. doi:10.1136/ bmjgh-2019-001482

Handling editor Seye Abimbola

Received 6 February 2019 Revised 15 April 2019 Accepted 19 April 2019

Check for updates

C Author(s) (or their employer(s)) 2019. Re-use permitted under CC BY-NC. No commercial re-use. See rights and permissions. Published by BMJ.

For numbered affiliations see end of article.

\section{Correspondence to}

Professor Felicity GoodyearSmith;

f.goodyear-smith@auckland. ac.nz

\section{ABSTRACT}

Introduction Since the Alma-Ata Declaration 40 years ago, primary healthcare (PHC) has made great advances, but there is insufficient research on models of care and outcomes-particularly for low-income and middleincome countries (LMICs). Systematic efforts to identify these gaps and develop evidence-based strategies for improvement in LMICs has been lacking. We report on a global effort to identify and prioritise the knowledge needs of PHC practitioners and researchers in LMICs about PHC organisation.

Methods Three-round modified Delphi using web-based surveys. PHC practitioners and academics and policymakers from LMICs sampled from global networks. First round (pre-Delphi survey) collated possible research questions to address knowledge gaps about organisation. Responses were independently coded, collapsed and synthesised. Round 2 (Delphi round 1) invited panellists to rate importance of each question. In round 3 (Delphi round 2), panellists ranked questions into final order of importance. Literature review conducted on 36 questions and gap map generated.

Results Diverse range of practitioners and academics in LMICs from all global regions generated 744 questions for PHC organisation. In round 2, 36 synthesised questions on organisation were rated. In round 3, the top 16 questions were ranked to yield four prioritised questions in each area. Literature reviews confirmed gap in evidence on prioritised questions in LMICs.

Conclusion In line with the 2018 Astana Declaration, this mixed-methods study has produced a unique list of essential gaps in our knowledge of how best to organise PHC, priority-ordered by LMIC expert informants capable of shaping their mitigation. Research teams in LMIC have developed implementation plans to answer the top four ranked research questions.

\section{INTRODUCTION}

The 1978 signing of the Alma-Ata Declaration called for the worldwide strengthening

\section{Key questions}

What is already known?

- Well-organised primary healthcare is essentia healthcare that forms an integral part of national health systems.

- Limited research is available from low-income and middle-income countries (LMICs) to inform decisions on implementing or improving primary healthcare models.

What are the new findings?

- Gaps in published evidence on priority areas for primary healthcare research identified by the expert panel are confirmed through systematic literature reviews.

What do the new findings imply?

- There is a need for research in LMICs on achieving holistic team-based full scope of care, appropriate referral, public-private partnerships, and coordination across policy and its practical application.

of primary healthcare (PHC), predominantly in low-income and middle-income countries (LMICs), ${ }^{1}$ and this is still needed today. Ideally, PHC incorporates community-based services covering health promotion, prevention, acute and chronic care management, through to palliative care and rehabilitation, delivered to individuals and families. ${ }^{2}$ However, in many countries, the initial implementation of Alma-Ata was a set of vertical programmes that targeted particular populations, ${ }^{3}$ rather than designing comprehensive people-centred 'horizontal' services, delivered by multidisciplinary teams. ${ }^{4}$ Characteristics of effective PHC include accessibility, affordability, and acceptability for people in all stages and ages of life. ${ }^{5}$ It works alongside other social sectors including education, welfare, housing and public works to address 
the social determinants of health. ${ }^{6}$ The Declaration also emphasised the importance of individual and community engagement in the organisation of PHC, including supporting people in self-care and self-management. ${ }^{1}$ The Astana Declaration of October 2018 reinforces the role of PHC and primary care (PC) services in achieving the aims of universal health coverage and the Sustainable Development Goals. It calls for governments to provide strong health systems, for communities to be empowered to enhance health and well-being, and alignments of stakeholders for effective support of national health policies. $^{7}$

A crucial component for modern PC delivery is a community-based medical workforce, known as family physicians, with postgraduate training for first point of medical care. ${ }^{4}$ These physicians take a holistic approach in caring for individuals and their families in the community and treat patients of all ages as their first contact for healthcare. ${ }^{8}$ They often work with teams of nurses, midwives and allied health professionals, deliver health promotion and prevention and other PHC services, and connect to other social and community welfare services, in addition to care and management of acute and chronic illness. ${ }^{9}$ In many rural and remote areas, PC is delivered by a non-physician workforce, with a family doctor based in a regional hospital acting as consultant.

Forty years later, PHC has strengthened and PHC research has advanced. However, this has been disproportionately focused on high-income countries (HICs), ${ }^{10} 11$ and most governments have been slow to recognise the importance of PHC research, even in HICs. ${ }^{12-14}$ Research priority setting exercises do occur in LMICs, but tend to be led by governments and international organisations, and have few implementation plans following the exercise. ${ }^{15}$ On the Alma Ata Declaration's 30th anniversary, WHO revealed some cases of exemplary PHC in LMIC, but also highlighted the underdeveloped nature of PHC in many parts of the world. ${ }^{1617}$

Analysis of 20 case histories of PHC from around the world has identified four common factors that have a positive impact on $\mathrm{PHC}$ research-development of academic departments and appointment of professors of family medicine; directed resources and funding; collaboration between different institutions, disciplines and settings; and the breadth and diversity of research conducted, to reflect the scope of PHC. ${ }^{18}$ PHC research grew where these factors were available; comparably, an absence of one or more of these themes was identified as a barrier to building research capacity.

High-quality research is needed to guide policy. Policy-makers often make decisions which fail to translate into effective change. The voice of healthcare providers and clinical academics has been absent in much PHC policy to date, and yet is of immense value if initiatives are to have traction at a community level. Over the past four decades, family medicine has evolved into a unique academic discipline within the broader PHC landscape. There are now departments of family medicine in many medical schools, often also extending into $\mathrm{PHC}^{8}$ PHC research has grown, and Index Medicus introduced Subject Heading 'Primary Health Care' (including Family Medicine) in 2010. Indexed journals that focus on general practice, family medicine and primary healthcare are now allocated to this subject. ${ }^{19}$ However, specialised bioscience agendas still dominate research. Many LMICs are still just establishing family medicine as a specialty, and have not achieved the same research capacity as some HICs, so PHC research in LMIC is particularly lacking.

As part of a larger funded project to ascertain the PHC research gaps in LMIC and develop research implementation plans, (ref BMJ GH Intro paper) we aimed to identify and prioritise the knowledge needs of PHC practitioners and researchers about how PHC can be organised, and different models of care for PC delivery.

\section{Objectives}

1. To produce a list of 16 prioritised research questions relevant to the needs for evidence on PHC in LMIC.

2. To produce a 'gap map', showing areas where there is existing evidence for questions perceived to be knowledge gaps, and where there are major gaps in evidence regarding questions about $\mathrm{PHC}$ organisation.

3. To prepare research implementation plans for the top four research questions identified.

\section{METHODS \\ Prioritised research questions development}

The study was conducted through our professional networks including the World Organization of Family Doctors (WONCA), the Robert Graham Center, the American Board of Family Medicine, and the Canadian Besrour Centre. The study involved a modified-Delphi panel consisting of PHC self-identified experts (family physicians, academics and policy-makers) from LMICs. Engaging clinical and academic staff working in PHC sectors is vital, as they understand the context of their own settings. ${ }^{20}$ The Delphi method is an iterative technique in which surveys are answered sequentially and anonymously by a diverse number of relevant experts, with summarised feedback to enable consensus. ${ }^{21}$ The World Bank list of economies was used to determine LMICs. ${ }^{22}$ We aimed for a diverse sample, with representation from LMICs in six global regions: Africa; Asia Pacific; South Asia; Latin America and the Caribbean; Eastern Mediterranean; Europe.

Invitations were sent to participants through our networks, enhanced by 'snowballing' (allowing invitees to disseminate the details to others whom they deemed eligible) ${ }^{23}$ We used a sampling matrix to ensure diverse representation in gender, age, residing country, location (rural or urban), role and discipline, and years of experience. Inclusion criteria were PHC practitioners or researchers residing and working in a LMIC with self-defined experience relevant to provide opinions on the key area of PHC national or regional organisation. 
Table 1 Demographics of LMIC panel responders

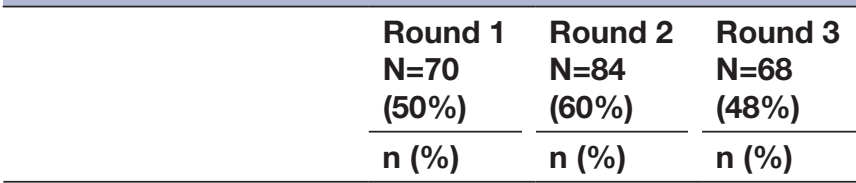

\section{Gender}

\begin{tabular}{|c|c|c|c|}
\hline Male & $42(60)$ & $46(55)$ & $39(57)$ \\
\hline Female & $28(40)$ & $38(45)$ & $29(43)$ \\
\hline \multicolumn{4}{|l|}{ Age in years } \\
\hline Under 30 & $2(3)$ & $4(5)$ & $3(4)$ \\
\hline 30-39 & $16(23)$ & $21(25)$ & 15 (22) \\
\hline $40-49$ & $22(31)$ & $24(29)$ & $18(27)$ \\
\hline $50-59$ & $18(26)$ & $22(26)$ & $22(32)$ \\
\hline 60 and over & $12(17)$ & $13(15)$ & $10(15)$ \\
\hline \multicolumn{4}{|l|}{ Work location } \\
\hline Urban & $50(71)$ & $62(74)$ & $52(76)$ \\
\hline Rural & $20(29)$ & $22(26)$ & $16(24)$ \\
\hline \multicolumn{4}{|l|}{ Global region* } \\
\hline Europe & $9(13)$ & $13(15)$ & $10(15)$ \\
\hline Africa & $31(44)$ & $35(42)$ & $31(46)$ \\
\hline Eastern Mediterranean & $1(1)$ & $1(1)$ & $1(1)$ \\
\hline South Asia & $10(14)$ & $11(13)$ & 7 (10) \\
\hline Asia Pacific & $6(9)$ & $6(7)$ & $6(9)$ \\
\hline $\begin{array}{l}\text { North America } \\
\text { Caribbean }\end{array}$ & $2(3)$ & $5(6)$ & $2(3)$ \\
\hline South America & $11(16)$ & $13(16)$ & $11(16)$ \\
\hline Health practitioner $†$ & $54(77)$ & $61(73)$ & $50(74)$ \\
\hline Family physician & $52(74)$ & $57(68)$ & $46(68)$ \\
\hline Other doctor & $1(1)$ & $3(4)$ & $3(4)$ \\
\hline Nurse & $1(1)$ & $1(1)$ & $1(1)$ \\
\hline $\begin{array}{l}\text { Years as health } \\
\text { professional }\end{array}$ & $54(77)$ & $61(73)$ & $50(74)$ \\
\hline$<5$ & $6(9)$ & $9(11)$ & $8(12)$ \\
\hline $5-10$ & $14(20)$ & $13(15)$ & $12(18)$ \\
\hline $11-15$ & $12(17)$ & $13(15)$ & $11(16)$ \\
\hline $16-20$ & $7(10)$ & $7(8)$ & $6(9)$ \\
\hline$>20$ & $15(21)$ & $19(23)$ & $13(19)$ \\
\hline Primary care academic $†$ & $55(79)$ & $58(69)$ & $47(69)$ \\
\hline Junior academic role & $24(34)$ & $37(44)$ & $20(29)$ \\
\hline Senior academic role & $31(44)$ & $21(25)$ & $27(40)$ \\
\hline Years as academic & $55(79$ & $58(69)$ & $47(69)$ \\
\hline$<5$ & $18(26)$ & $17(20)$ & $12(18)$ \\
\hline $5-10$ & $19(27)$ & $24(29)$ & $19(28)$ \\
\hline $11-15$ & $5(7)$ & $7(8)$ & $3(4)$ \\
\hline $16-20$ & $7(10)$ & $5(6)$ & $8(12)$ \\
\hline$>20$ & $6(9)$ & $5(6)$ & $5(7)$ \\
\hline Policy-maker & $18(26)$ & $16(19)$ & $14(21)$ \\
\hline Years as policy-maker & $18(26)$ & $16(19)$ & $14(21)$ \\
\hline
\end{tabular}

Table 1 Continued

\begin{tabular}{|c|c|c|c|}
\hline & $\begin{array}{l}\text { Round } 1 \\
\mathrm{~N}=70 \\
(50 \%)\end{array}$ & $\begin{array}{l}\text { Round } 2 \\
\mathrm{~N}=84 \\
(60 \%)\end{array}$ & $\begin{array}{l}\text { Round } 3 \\
N=68 \\
(48 \%)\end{array}$ \\
\hline & n (\%) & n (\%) & n (\%) \\
\hline$<5$ & 9 (13) & $6(7)$ & $5(7)$ \\
\hline $5-10$ & $5(7)$ & $6(7)$ & $4(6)$ \\
\hline $11-15$ & 2 (3) & $2(2)$ & 2 (3) \\
\hline 16-20 & $1(1)$ & 2 (2) & $1(1)$ \\
\hline$>20$ & $1(1)$ & $0(0)$ & 2 (3) \\
\hline
\end{tabular}

*WONCA global regions (see http://www.globalfamilydoctor.com/ AboutWonca/Regions.aspx).

†All policy-makers also hold other roles, hence total $>100 \%$.

LMIC, low-income and middle-income country.

The limited time available precluded survey translations, hence an exclusion criterion was insufficient fluency in written English. People of LMIC origin now living and working in a HIC were excluded. WONCA LMIC leaders piloted round 1 prior to panel circulation to ensure that it was comprehensible to participants with English as a second language, as well as quick and easy to respond to. ${ }^{24}$ Modifications were made in response to their feedback.

The timeline to recruit the expert panel and conduct three rounds of Delphi was 3 months. The aim of the first round was qualitative- to generate as many research questions as possible. The subsequent two rounds followed a modified Delphi technique, providing anonymised summaries of panellists' responses between rounds to facilitate group convergence.

Respondents meeting inclusion criteria were recruited as panellists in January 2018. The survey was delivered by Qualtrics, a web-based survey tool. To protect the identity of panellists, participant demographics were limited to residing region and country; rural or urban; age (range); gender current role(s) (practitioner including type, academic, policy-maker); and years of experience. Ethical approval for the study was obtained from the University of Auckland Human Participants Ethics Committee (Ref 020630).

In round 1, participants were asked to generate research questions about gaps in knowledge of organisation of PHC relating to workforce, models of care, use of teams, scope of care, transitions of care and government policy. Enrolled panellists were sent invitations to the survey through individual links. Using a general inductive thematic approach, questions generated by the panellists were collated and coded into domains, categories and subcategories. ${ }^{25}$ The first 25 respondent replies were coded by two independent researchers and Cicchetti-Allison kappa coefficient calculated to check for reliability. Data were sorted by codes, collapsed and synthesised to lists of questions for the key area. Where similarities emerged in questions from multiple participants, investigators worked towards consensus in creation of a combined and representative question for round 2. 
Table 2 Thirty-six research questions for PHC organisation rated for importance

\section{Organisation/models of care}

Sum Mean

1. How can family physicians be supported to provide comprehensive community-based care 290 instead of resources being directed into vertical programmes?

2. What are the drivers for PHC teams to deliver high-quality services (intrinsic and extrinsic factors 286 such as pay, status, career pathway/promotion etc)?

3. How can education and training support the PHC workforce to deliver the range of services that 284 address priority health needs of the community?

4. How does PHC impact the health indicators of the countries? What are these indicators? How 284 are they measured? How do they compare between countries?

5. What are the factors that facilitate recruitment and retention of a PHC workforce in underserved 280 community settings?

6. What are the best strategies to implement and monitor best practice in PHC? 3.46

7. Are the services and scope of practice of PHC aligned with people's health needs, considering $279 \quad 3.44$ variations in population needs, resources and geography, and what is the evidence on which the range of services/scope of care provided should be decided?

8. What strategies can be undertaken to ensure quality in the delivery of PHC service to patients $279 \quad 3.44$ (eg, training/research/quality control)?

9. What are the factors or incentives that can improve distribution of PHC workforce or equity of $277 \quad 3.42$
accessing PHC services?

10. How can different stakeholders (eg, policy-makers, health system managers, health workforce $277 \quad 3.42$ organisations, academic institutions and communities) support and assist the PHC workforce and successful team functioning?

\begin{tabular}{|c|c|c|c|}
\hline 11. & How can PHC services be integrated with other community-based health and social services? & 276 & 3.41 \\
\hline 12. & $\begin{array}{l}\text { What are the factors to be considered and negotiated for successful referral from primary to } \\
\text { secondary care and back? }\end{array}$ & 275 & 3.40 \\
\hline 13. & $\begin{array}{l}\text { What PHC models of care provision in resourced limited environments provide the highest } \\
\text { impact? }\end{array}$ & 274 & 3.38 \\
\hline 14. & $\begin{array}{l}\text { How should care be horizontally integrated and coordinated among the multidisciplinary PHC } \\
\text { team? }\end{array}$ & 273 & 3.37 \\
\hline 15. & $\begin{array}{l}\text { What factors should determine the composition of the PHC team and what professionals should } \\
\text { the team include as a minimum? }\end{array}$ & 270 & 3.33 \\
\hline 16. & $\begin{array}{l}\text { What are the essential features to ensure adequate coordination and collaboration among PHC } \\
\text { team members to address the priority health concerns of the population they serve? }\end{array}$ & 270 & 3.33 \\
\hline 17. & $\begin{array}{l}\text { What procedures and protocols are required to ensure seamless transitions and transfers occur } \\
\text { when required to and from primary and secondary care? What role can IT play in this? }\end{array}$ & 269 & 3.32 \\
\hline 18. & $\begin{array}{l}\text { What is the best leadership model for PHC? Who should lead the PHC delivery team where there } \\
\text { is no physician? }\end{array}$ & 268 & 3.31 \\
\hline 19. & $\begin{array}{l}\text { How can different stakeholders (eg, health system managers, health workforce members, } \\
\text { academic institutions and communities) advise policy-makers on how to ensure that PHC } \\
\text { services address population health needs? }\end{array}$ & 268 & 3.31 \\
\hline 20. & $\begin{array}{l}\text { What can be done to prioritise limited resources and what alternatives including telemedicine } \\
\text { can assist in providing PHC to under-resourced areas? }\end{array}$ & 264 & 3.26 \\
\hline 21. & $\begin{array}{l}\text { What tools and processes are best for assessing the match between PHC team structure and } \\
\text { function and patient/community needs? }\end{array}$ & 263 & 3.25 \\
\hline 22. & $\begin{array}{l}\text { What is the effective panel (patient population) size for provision of effective, comprehensive } \\
\text { PHC? How does this differ depending on worker type, PHC team composition and location (eg, } \\
\text { urban vs rural)? }\end{array}$ & 259 & 3.20 \\
\hline 23. & $\begin{array}{l}\text { How does a PHC team establish practice priorities, what essential services need to be provided } \\
\text { and decide what is out of scope? }\end{array}$ & 255 & 3.15 \\
\hline 24. & $\begin{array}{l}\text { Are there differences in the ability to access PHC based on the region of the country, and } \\
\text { between rural and urban? }\end{array}$ & 254 & 3.14 \\
\hline 25. & $\begin{array}{l}\text { What are the most useful ways of delineating PHC services and hospital services in a generalist } \\
\text { district health system model? }\end{array}$ & 253 & 3.12 \\
\hline
\end{tabular}




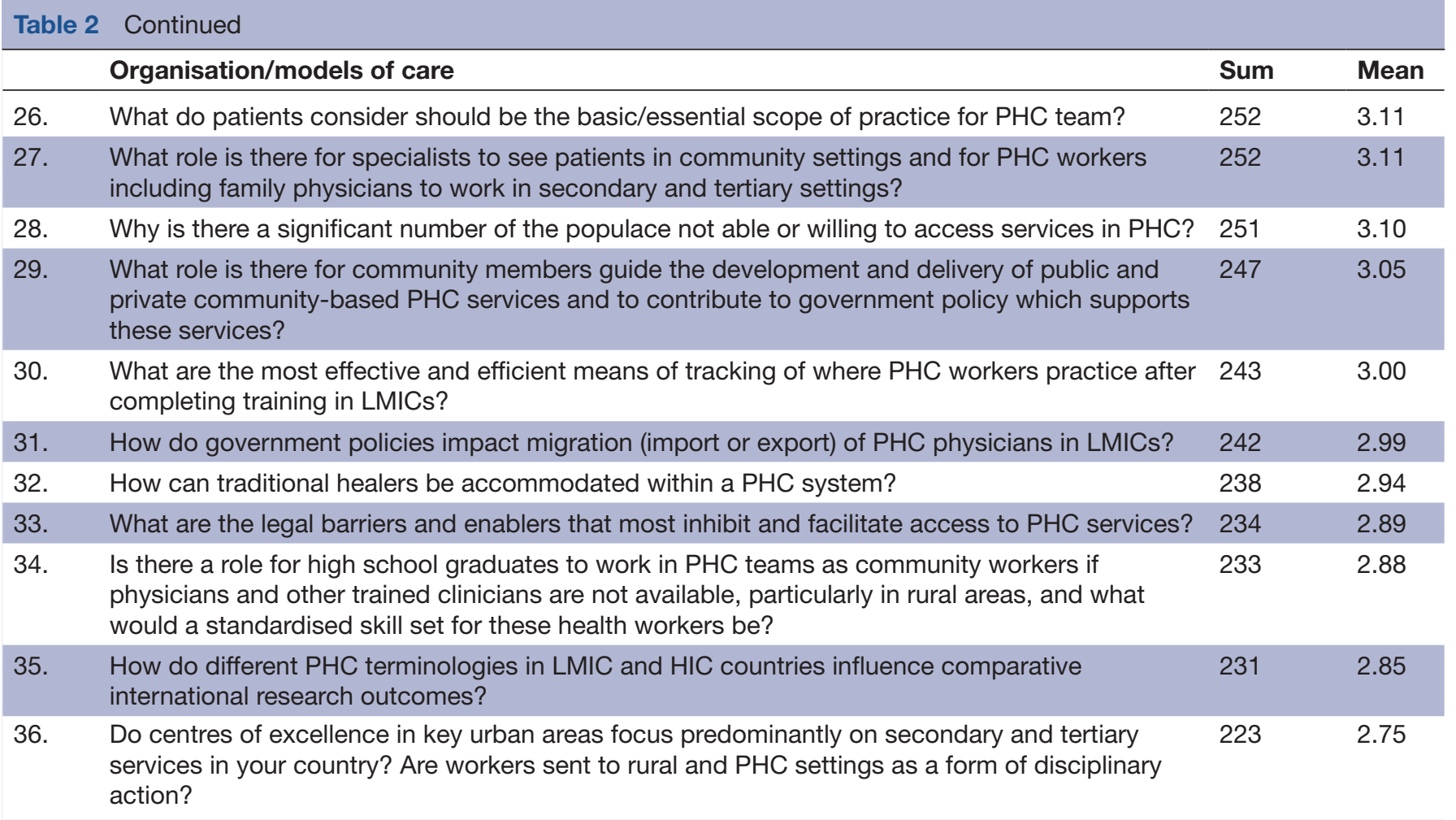

Maximum possible score $=336$ (if all panellists rated the question very important).

LIC, low-income country; LMIC, low-income and middle-income country; PHC, primary healthcare.

In round 2, all enrolled participants were invited to rate each question to determine the importance within their county using a four-point Likert scale. The question lists were presented to each participant randomly to prevent response bias from the order of presentation. Agreement of the participants' responses was calculated, determined by mean score. Collated responses were ordered in degree of importance, and the top 16 research questions were selected.

In round 3, the research questions again were randomly presented, and panellists were asked to rank these 16 research questions within Qualtrics by order of importance for their country, to establish the top four. SAS V.9.3 (SAS Institute, Cary, North Carolina, USA) was used to perform statistical analyses.

The funder (Ariadne Labs through the Bill and Melinda Gates Foundation) is concurrently funding similar research priority setting exercises on PHC quality and safety, and on policy and governance. Some of the questions relating more to these areas than PHC organisation were removed. Our team was separately conducting the same exercise for PHC financing, and one of the top-ranking questions in this area fitted better into PHC organisation, so was shifted. The four highest-ranking questions relating to PHC organisation were selected for the subsequent formulation of research implementation plans.

\section{Patient and public involvement}

Patients were not involved in this study. The aim was to identify and prioritise the knowledge needs of PHC practitioners, researchers and policy-makers in LMICs. The study involved considerable input from, and co-design with, professionals from LMICs, but patient participation in this context was not appropriate.

\section{Scoping literature review}

Literature reviews were conducted to test whether there was already a LMIC literature base for the research questions generated by the panel. Thirty-six searches were conducted, one for each question. We constructed a two-dimensional coding matrix using the Primary Health Care Performance Initiative (PHCPI) conceptual framework for one axis and the dimensions of PHC organisation identified through coding the questions generated in round 1 by the panel for the other axis. The coding matrix was designed to search for specific answers to the generated questions. A selection of the searches was conducted by two researchers independently to reduce researcher bias and check for coding consistency. ${ }^{26}$

The search was completed using a string of terms for PHC and LMICs since 2003, MeSH and/or text words [tw]/or title and abstract words [tiab] relating to the specific domain or subdomain from the coding matrix.

Inclusion criteria were studies conducted in LMICs within the last 15 years in PHC or family practice, with $\mathrm{MeSH}$ or key terms related to the questions of interest. Commentaries were excluded. Searching over a limited period is an accepted technique for conducting rapid reviews. ${ }^{27}$ The studies were screened for relevance, and 


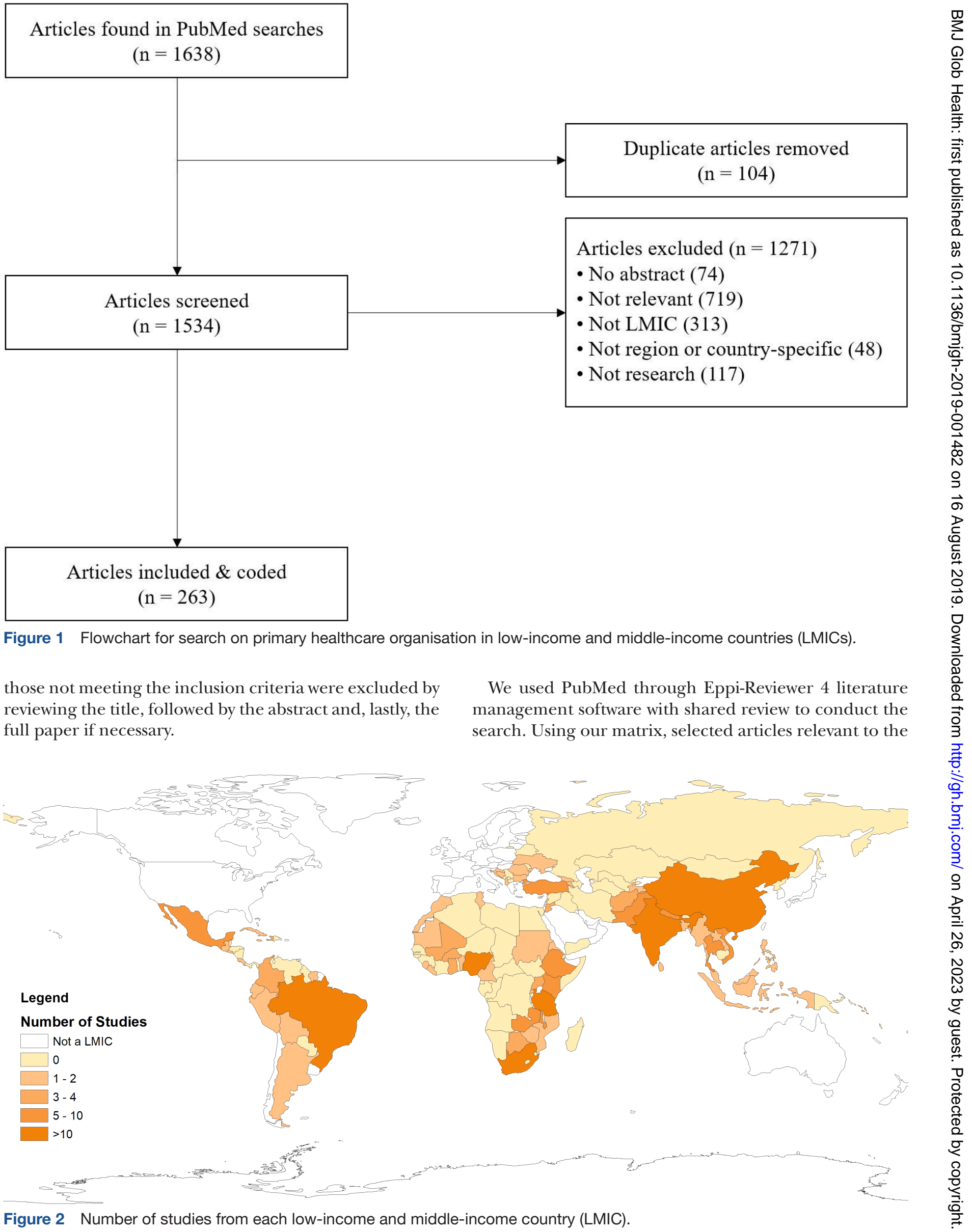




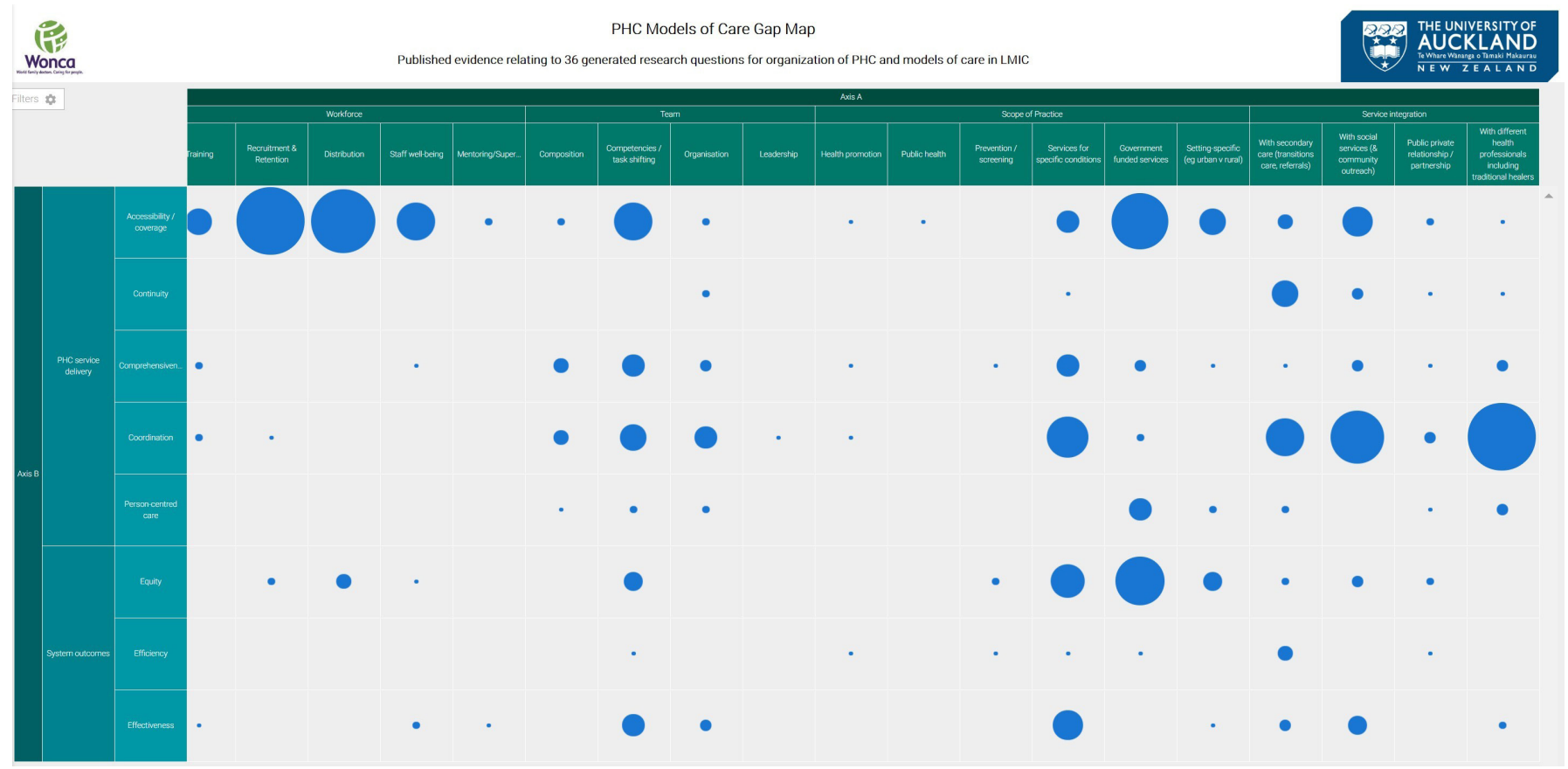

Figure 3 Static version of gap map of studies for model of care.

question were coded for two axes. Seven global regions (Europe, Eastern Mediterranean, Asia Pacific, South Asia, Africa, North America, South America) and a list of all LMICs were included as filters for the map.

\section{Gap map}

A gap map does not answer specific research questions, but rather provides a broad overview of existing evidence. Our map was created to determine whether there is existing evidence on the questions generated by our panellists. It required development of a coding framework of the interventions and outcomes of interest. ${ }^{26}$ The PHCPI framework and the generated research questions informed our selection of domains, categories and subcategories for our conceptual framework. Once all selected articles were coded, Eppi-Reviewer 4 software providers created our gap map, which displays a visual heat map of available evidence and the gaps related to the 36 research questions.

\section{Research implementation plans}

Panellists were invited to submit expressions of interest to prepare an implementation plan for a specific LMIC for one of the top four questions. Researchers were selected based on their known track record in PHC research and their capacity to develop a research team. Their submitted draft plans were used at a workshop run by members of the research team at the WONCA Europe conference in Krakow, Poland in May 2018. During the workshop, small groups of researchers critiqued the plans and provided feedback which was supplied to those preparing the plans to help refine them.

\section{RESULTS}

\section{Prioritised research questions}

There were 141 Delphi panellists enrolled in the study from 50 LMICs from all global regions. Asia Pacific and the Eastern Mediterranean (ie, North Africa and the Middle East) were relatively under-represented. Seventy $(50 \%)$ completed round 1 with a broad range of demographic characteristics (table 1). Numerous participants held more than one role. Some health practitioners also indicated they were academics or policy-makers; others explained that they held all three positions.

Independent coding of the first 25 survey responses showed a high degree of consistency with a Cicchetti-Allison kappa coefficient weight $\kappa=0.879$ (95\% CI 0.7345 to 1.000$) \mathrm{p}$ value $<0.0001$ (almost perfect agreement). In the final LMIC dataset, 744 valid generated questions or responses were coded. Round 2 was completed by $84(60 \%)$ of the enrolled participants (see table 1 ). All 36 questions including the top 16 when ratings were summed are shown in table 2 . Round 3 was completed by $68(48 \%)$ of enrolled participants. One of the top ranked questions in our parallel financing of PHC project ('How can the public and private sectors work more collaboratively to improve and integrate PHC coverage and prevent segmentation of the services?') was moved here. The research team subsequently discussed the general feasibility of the questions to be answered and moved some to higher priority.

The final top four ranked questions are:

1. What are the factors to be considered and negotiated for successful referral from primary to secondary care and back? 
Table 3 Country-specific questions developed for the top four prioritised questions

\begin{tabular}{|c|c|c|c|}
\hline Country & Research question & Aims & Methods \\
\hline Brazil & $\begin{array}{l}\text { What are the factors to be } \\
\text { considered and negotiated } \\
\text { for successful referral from } \\
\text { primary to secondary care } \\
\text { and back in Brazil? }\end{array}$ & $\begin{array}{l}\text { 1. To identify factors that influence } \\
\text { referral between primary and } \\
\text { secondary care in Brazilian context } \\
\text { 2. To test and develop strategies to } \\
\text { improve communication between } \\
\text { primary and secondary care within } \\
\text { the main systems of referral in Brazil }\end{array}$ & $\begin{array}{l}\text { Involve all five national health } \\
\text { regions, target populations, family } \\
\text { physicians and nurse practitioners; } \\
\text { PHC and hospital workers; municipal } \\
\text { health managers } \\
\text { Phase } 1 \text { Online national } \\
\text { questionnaire and semistructured } \\
\text { interviews } \\
\text { Phase } 2 \text { Regional case studies } \\
\text { in eight cities (in four regions) of } \\
\text { successful referral to identify barriers } \\
\text { and best practice. Methods include } \\
\text { therapeutic inventory, focus groups } \\
\text { Phase } 3 \text { Using participatory } \\
\text { methodology, develop intervention } \\
\text { plans in each region }\end{array}$ \\
\hline Malaysia & $\begin{array}{l}\text { How can the public and } \\
\text { private sectors work } \\
\text { more collaboratively to } \\
\text { improve and integrate } \\
\text { PHC coverage and prevent } \\
\text { segmentation of services in } \\
\text { Malaysia? }\end{array}$ & $\begin{array}{l}\text { 1. To determine the perception and } \\
\text { experience of providing care in } \\
\text { their own sector of public and } \\
\text { private primary care practitioners, } \\
\text { the constraints they identify and } \\
\text { the access to services in the other } \\
\text { sector to which they would like to } \\
\text { have access } \\
\text { 2. To determine the mechanisms used } \\
\text { by people in the community to } \\
\text { decide whether to access public or } \\
\text { private primary care services when } \\
\text { unwell }\end{array}$ & $\begin{array}{l}\text { Phase } 1 \text { Explore perception and } \\
\text { experience of public and private } \\
\text { primary care practitioners on } \\
\text { constraints and access to services } \\
\text { that they wish they could have to the } \\
\text { other sector using mixed qualitative } \\
\text { and quantitative method approach } \\
\text { Phase } 2 \text { Nationwide survey of } \\
\text { public physicians, pharmacists, } \\
\text { public health physicians and } \\
\text { health directors, and private family } \\
\text { physicians to identify, confirm } \\
\text { and estimate degree of healthcare } \\
\text { services segmentation }\end{array}$ \\
\hline
\end{tabular}

Team

Assist Prof Sandro

Rodrigues Batista (lead)

Assoc Prof Sandra Fortes

Adjunct Prof Clara Aleida

Prada Sanabria

Assist Prof Rita De Cassia

Nascimento

Prof Fernanda K Melchior

Silva Pinto

Prof João Mazzoncini De

Azevedo Marques

Prof Tiago Sarti

Prof Leonardo Moscovici

Phase 3 Using participatory plans in each region

hase 1 Explore perception and experience of public and private primary care practitioners on

Prof Dr Sherina Mohd Sidik

(lead)

Assoc Prof Dr Chew Boon

How

Assoc Prof Dr Ambigga Devi

Krishnapillai

Dr Aida Jaafar

Dr Maizatullifah Miskan

Dr Hasliza Abu Hassan

Dr Ng Kien Keat

Assoc Prof Dr Aznida Firzah

Abdul Aziz

Assoc Prof Dr Noor Azimah

Muhammad

Dr Ummavathy Periasamy

Dr Muhambigai Perumal

Samy

Vigneswary Perumal Samy

\begin{tabular}{|c|c|c|c|c|c|}
\hline Nigeria & $\begin{array}{l}\text { How can different } \\
\text { stakeholders support } \\
\text { and assist the primary } \\
\text { healthcare workforce and } \\
\text { successful team functioning } \\
\text { in Nigeria? }\end{array}$ & & $\begin{array}{l}\text { To assess perceptions, knowledge } \\
\text { to practice gap and examine } \\
\text { experiences of PHC stakeholders } \\
\text { with the use of proven approaches } \\
\text { for support and assistance for } \\
\text { PHC workforce and PHC team } \\
\text { functioning in Nigeria } \\
\text { To incorporate the information } \\
\text { generated from perceptions } \\
\text { and knowledge to practice gap } \\
\text { assessment into a family physician- } \\
\text { led Supportive Supervisory Module } \\
\text { and test its effectiveness for } \\
\text { supportive supervision in } 8 \text { PHC } \\
\text { centres in } 2 \text { of the } 36 \text { States in } \\
\text { Nigeria }\end{array}$ & $\begin{array}{l}\text { Qualitative methods to explore and } \\
\text { examine experiences and interpret } \\
\text { perceptions of PHC stakeholders } \\
\text { with the use of proven approaches } \\
\text { for support and assistance of PHC } \\
\text { workforce and PHC team functioning } \\
\text { Quasi-experimental design to } \\
\text { test use of a family physician-led } \\
\text { supportive supervision module and } \\
\text { patient care support to improve } \\
\text { PHC team functioning and provider } \\
\text { competency in clinical case } \\
\text { management in } 4 \text { PHC centres in } \\
\text { four States in Nigeria }\end{array}$ & $\begin{array}{l}\text { Dr Aboi JK Madaki (lead) } \\
\text { Prof Udonwa Ndifreke } \\
\text { Dr Akin Moses } \\
\text { Dr Irabor Achiaka }\end{array}$ \\
\hline $\begin{array}{l}\text { South } \\
\text { Africa }\end{array}$ & $\begin{array}{l}\text { How should care be } \\
\text { horizontally integrated and } \\
\text { coordinated among the } \\
\text { multidisciplinary primary } \\
\text { healthcare team in South } \\
\text { Africa? }\end{array}$ & $\begin{array}{l}1 . \\
2 . \\
3 .\end{array}$ & $\begin{array}{l}\text { Describe the multidisciplinary team } \\
\text { composition for community practice } \\
\text { in South Africa } \\
\text { Compare outcomes of care in all } \\
\text { sites of interest and related controls } \\
\text { Implementation outcomes such as } \\
\text { feasibility, cost, reach and accept }\end{array}$ & $\begin{array}{l}\text { Describe the multidisciplinary team } \\
\text { composition for community practice } \\
\text { Develop } 4-6 \text { new community } \\
\text { practices within existing community } \\
\text { health centres using community } \\
\text { oriented primary care principles: } \\
\text { key stakeholders engaged, CHWs } \\
\text { deployed into defined population } \\
\text { served, practice orientation to } \\
\text { community, and targeted health } \\
\text { promotion in } 4-6 \text { urban-rural sites } \\
\text { identified by each Department of } \\
\text { Family Medicine } \\
\text { Use existing, validated practice } \\
\text { evaluation tools (mixed method) } \\
\text { to assess differences in outcomes } \\
\text { relative matched practices in the } \\
\text { same communities to discern } \\
\text { important differences in team } \\
\text { composition }\end{array}$ & $\begin{array}{l}\text { Prof Shabir Moosa (lead) } \\
\text { The } 8 \text { Departments of Family } \\
\text { Medicine in South Africa will } \\
\text { be approached to join this } \\
\text { project as partners }\end{array}$ \\
\hline
\end{tabular}
workforce and $\mathrm{PHC}$ team functioning Quasi-experimental design to test use of a family physician-led supportive supervision module and patient care support to improve competency in clinical case management in $4 \mathrm{PHC}$ centres in four States in Nigeria

Describe the multidisciplinary team composition for community practice 4-6 new community health centres using community oriented primary care principles: served, practice orientation to munity, and targeted health identified by each Department of Family Medicine composition 
2. How should care be horizontally integrated and coordinated among the multidisciplinary PHC team?

3 . How can the public and private sectors work more collaboratively to improve and integrate PHC coverage and prevent segmentation of the services?

4. How can different stakeholders (eg, policy-makers, health system managers, health workforce organisations, academic institutions and communities) support and assist the primary healthcare workforce and successful team functioning?

\section{Literature review}

Figure 1 shows the flowchart for the literature review.

Two hundred and sixty-three articles met the inclusion criteria, which were coded according to the matrix for the two axes, plus region and country for the filters (references included as online supplementary appendix 1). All regions of the world were represented, with the most studies in Africa (93), followed by Latin America and the Caribbean (60), Asia/Pacific (47), South Asia (18), Europe (18) and lastly Eastern Mediterranean (13) (figure 2).

\section{Gap map}

The gap map was created through Eppi-Reviewer (Gapmap MOC). A static version is displayed in figure 3. The interactive web-based map presents both a heat map and a bubble map, with LMIC and global region filters. It enables viewing of all studies in a cell by clicking on the bubble.

\section{Research implementation plans}

It is clear that there are significant gaps, and the questions generated by our panellists have not been previously answered. Country-specific research implementation plans were developed for the top four questions (table 3).

\section{DISCUSSION}

\section{Summary of results}

The number and diversity of our LMIC panellists, and their responses across our three rounds of question generation, rating and ranking, exceeded our expectations. There were many common themes in the questions submitted, and the following two rounds produced four questions. Three examine the ways PHC may be better integrated-vertically with secondary care, horizontally with other community-based services, and between the private and public sectors. The fourth looks at the overall system and ways political, academic and community agencies may work together to support PHC. The literature reviews confirmed a lack of evidence around these topics in LMIC.

A number of themes in the literature review related to optimal team-based care, access to and geographical distribution of PC services, integration and coordination between primary and secondary care, and what PHC should incorporate. The results also present degree of alignment with the Framework for Integrated People-Centered Health Services, which advocates that all people have access to health services that are coordinated around their needs, respects their preferences, and are safe, effective, timely, affordable and acceptable. ${ }^{28}$

The research questions generated have a strong focus on the position of PHC in the health system, and its relation to hospitals and secondary care specialists. This may signal the challenges faced to prioritise PHC in health systems traditionally centred on hospital care. While some district hospitals, especially in LICs, may deliver PHC services, these tend to be first contact and community-focused care. For example, family physicians may work out to of the district hospitals and see patients at community clinics who have been triaged by nurses. It is important to acknowledge this reality, but also keep track of the importance of horizontal links of PHC to other community-based sectors that impact on population health. ${ }^{10}$ The new Astana Declaration 40 years calls for a move beyond how health services have been traditionally structured, to how health services need to be organised to advance health equity and support people to actively participate in the maintenance of their health status. ${ }^{729}$ Insight into the most important health problems in the population under care should inform the development of PHC. Such insight would be relevant for a number of the research questions that were generated, for example, in relation to practice priorities, the interface of $\mathrm{PHC}$ and hospital care, or teaching and training. Often, exploring health problems in the PHC setting has been the first step to successful PHC research. ${ }^{30}$

\section{Strengths of the study}

The rapid recruitment of a diverse range of PHC experts from across LMIC indicates the strong interest in the PHC sector in LMIC for research into health service delivery and systems to inform practice and policy. Our use of the same panel for assessing both organisation and financing knowledge gaps added rigour because the development of effective PHC organisation and models of care cannot be isolated from mechanisms of funding. A sister paper presents the findings for the latter, but evidence from WONCA comparative studies on PHC policy implementation ${ }^{31-34}$ highlights the need for an integrated coherent approach.

Our consistent use of a bottom-up approach, with questions generated by stakeholders and the searching for possible evidence already available for their prioritised questions, was a further strength. We have used researchers in LMICs who know their own contexts to develop implementation plans relevant to their own country or region's needs and resources. And within the constrained funding time, it was also possible to generate four pilot plans for research implementation. This commitment and speed of proposal development by LMIC research teams supports our opinion that the bottom-up approach is more likely to lead to research acceptable to front-line practices. It may also offer policy-makers policy-relevant 
options that translate into effective change. This study therefore contributes to potential reforms on the most urgent needs in local contexts.

The large number of initial research questions and significant gaps in LMIC literature suggest a broader evidence gap in LMIC, but our process highlights bottom-up prioritisation with our use of Delphi processes enabling maintenance and development of consensus. ${ }^{35}$ WONCA's rich network of PHC relationships made it possible to recruit a robust response within tight time constraints. It also made it possible to recruit LMIC leaders for the development of derivative study proposals, another 'bottom-up' approach.

A further strength was the robust qualitative methodology which achieved a high degree of inter-rater coding reliability and which supported an iterative Delphi approach which produced prioritised research questions.

\section{Limitations of the study}

We were restricted by time and resources to conducting our surveys in English, and the majority of African panellists came from Anglophone countries. Most panellists were family physicians with a specific medical emphasis on issues they experience and are concerned aboutthese may or may not reflect the concerns of other PHC professionals, such as nurses or community health workers. Time constraints limited our ability to disseminate our panel invitation widely through other networks. We note, however, that in round 2, only two proposals mentioned family physicians specifically, and only one of these reached round 3 .

We were unable to conduct the literature reviews as robustly as we would have liked, given the time constraint. Studies were mostly screened based on the abstract, those lacking an abstract were excluded and there was an English language bias. Only the PubMed database was searched and no grey literature.

\section{CONCLUSION}

Clearly the evidence gap is very real, and there is no robust body of literature that answers our proposed priority questions. Research is needed in LMICs that focuses on models of PHC. This should be done as widely as possible, evaluating different countries and settings, so that findings are transferable. There may be a lack of PHC services in many countries, but this should shift as countries seek to undertake to deliver strong PHC for universal health coverage. As implementation occurs, the four key questions-achieving holistic team-based full scope of care, appropriate referral, public-private partnerships, and coordination across policy and its practical application-can be researched in the field and lessons learnt. Methods of quality improvement and action research may be applicable in live settings, and funding needs to follow these experiments in healthcare delivery. Health in LMICs depends on PHC and the efficient allocation of scarce resources-this seminal exercise is uniquely suited to inform global funders and health systems on the next steps needed to create evidence towards the effective organisation of PHC.

\section{Author affiliations}

${ }^{1}$ Department of General Practice and Primary Health Care, University of Auckland Faculty of Medical and Health Sciences, Auckland, New Zealand

${ }^{2}$ Robert Graham Center Policy Studies in Family Medicine and Primary Care, Washington, District of Columbia, USA

${ }^{3}$ McGill University, Montreal, Quebec, Canada

${ }^{4}$ Primary Care, University of East Anglia Norwich Medical School, Norwich, UK ${ }^{5}$ Department of Family and Community Medicine, University of Toronto and Southgate Institute for Health, Toronto, Ontario, Canada

${ }^{6}$ Flinders University, Adelaide, South Australia, Australia

${ }^{7}$ Research and Policy of the American Board of Family Medicine, Lexington, Kentucky, USA

${ }^{8}$ Radboud Institute of Health Research, Department Primary and Community Care, Radboud Universiteit Nijmegen, Nijmegen, The Netherlands

${ }^{9}$ Department of Health Services Research and Policy, Australian National University, Acton, Australian Capital Territory, Australia

Acknowledgements We gratefully acknowledge Drs Asaf Bitton, Director and Lisa Hirschhorn, Senior Advisor of Primary Health Care, Ariadne Labs for their support and assistance with this study. We also wish to acknowledge David Peiris and his team at the George Institute for Global Health whose work informed our coding matrix, and to thank them for sharing their material with us and recommending use of Eppi-Reviewer 4. The bid for this work was made with the agreement of WONCA World Executive. Members Dr Henry Lawson, Regional resident for Africa; Professor Kanu Bala, Regional president for South Asia; and Dr Inez Padula, regional President for South America, supported the original bid. We also wish to acknowledge the lead researchers of the four implementation plans and their teams: Dr Sandro Rodrigues, School of Medicine, Federal University of Goiás, Brazil; Professor Shabir Moosa, Department of Family Medicine, University of Witwatersrand, South Africa; Professor Sherina Mohd-Sidik, Universiti Putra Malaysia, Malaysia; and Dr Aboi Madaki, Department of Family Medicine, University of Jos, Nigeria.

Contributors FG-S: led the proposal, study design and research implementation; conducted qualitative analysis, oversaw other analyses, drafted initial paper and revised. AB: involved in developing the proposal on which this article is based, is on the core project team, helped advise on methods development and contributed to consecutive versions of the article. MC: conducted qualitative data analysis, refined qualitative coding process and edited publication documents. RDWF: made substantial contributions to study design, data collection, qualitative and quantitative data analyses, and to the draft and critical revision of the manuscript. $\mathrm{AH}$ : involved in the bid for the work on which this article is based, is on the core project team, had input to methods development and commented on consecutive versions of the article. MK: involved in the bid for the work on which this article is based, is on the core project team and had input to all versions of the article. RP: involved in developing the proposal on which this article is based, is on the core project team, helped advise on methods development and contributed to consecutive versions of the article. KR: participated in initial discussions about the project and in two teleconferences, and provided input into the documents. CvW: involved in the bid for the work on which this article is based, is on the core project team and had input to all versions of the article.

Disclaimer This publication is based on research funded by Ariadne Labs through Brigham and Women's Hospital, which is the recipient of a Bill and Melinda Gates Foundation grant. The findings and conclusions contained within are those of the authors and do not necessarily reflect positions or policies of the Bill and Melinda Gates Foundation.

Competing interests None declared.

Patient consent for publication Not required.

Ethics approval University of Auckland Human Participants Ethics Committee (ref. 020630).

Provenance and peer review Not commissioned; externally peer reviewed.

Data availability statement All data relevant to the study are included in the article or uploaded as online supplementary information. 
Open access This is an open access article distributed in accordance with the Creative Commons Attribution Non Commercial (CC BY-NC 4.0) license, which permits others to distribute, remix, adapt, build upon this work non-commercially, and license their derivative works on different terms, provided the original work is properly cited, appropriate credit is given, any changes made indicated, and the use is non-commercial. See: http://creativecommons.org/licenses/by-nc/4.0/.

\section{REFERENCES}

1. International Conference on Primary Health Care. Declaration of Alma-Ata. Alma-Ata: USSR: WHO, 1978.

2. Labonté R, Pooyak S, Baum F, et al. Implementation, effectiveness and political context of comprehensive primary health care: preliminary findings of a global literature review. Aust J Prim Health 2008;14:58-67.

3. Tarimo E, Webster E, World Health Organization. Primary health care concepts and challenges in a changing world: Alma-Ata revisited. Geneva: WHO, 1994.

4. World Health Assembly. Primary health care, including health system strengthening WHA6212. Geneva: 22nd World Health Assembly, WHO, 2009: 3

5. Starfield B. Measuring the attainment of primary care. J Med Educ 1979;54:361-9.

6. Thomas S. Doctors for Health Equity - World Medical Association Report. London, UK World Medical Association; 2016: 86.

7. World Health Organization. Astana declarartion: from Alma-Ata towards universal health coverage and the Sustainable Development Goals. Astana, Kazakhstan: Global Conference on Primary Health Care, 2018: 12.

8. Goodyear-Smith F. The history of primary care research. In: Goodyear-Smith F, Mash B, eds. International perspectives on primary care research. London: CRC Press, Taylor \& Francis Group, 2016: 5-10.

9. Phillips RL, Brundgardt S, Lesko SE, et al. The future role of the family physician in the United States: a rigorous exercise in definition. Ann Fam Med 2014;12:250-5.

10. Labonte R, Spiegel J. Setting global health research priorities. BMJ 2003;326:722-3.

11. Yoshida S. Approaches, tools and methods used for setting priorities in health research in the 21(st) century. J Glob Health 2016;6.

12. Rosser WW, van Weel C. Research in practice is essential for improving health globally. Ann Fam Med 2004;2(suppl_2):S2-S4.

13. Beasley JW, Starfield B, van Weel C, et al. Global health and primary care research. J Am Board Fam Med 2007;20:518-26.

14. Lucan SC, Phillips RL, Bazemore AW. Off the roadmap? Family medicine's grant funding and committee representation at $\mathrm{NIH}$. Ann Fam Med 2008;6:534-42.

15. McGregor S, Henderson KJ, Kaldor JM. How are health research priorities set in low and middle income countries? A systematic review of published reports. PLoS One 2014;9:e108787.
16. World Health Organization. The World Health Report 2008: primary health care-now more than ever. Geneva: World Health Organization, 2008.

17. Phillips RL, Bazemore AW. Primary care and why it matters for U.S. health system reform. Health Aff 2010;29:806-10.

18. Goodyear-Smith F, Mash B. International perspectives on primary care research. London: CRC Press, 2016.

19. Goodyear-Smith F. JPHC achieves Medline status. J Prim Health Care 2010;2:178-9.

20. Whyte W. Participatory action research. Thousand Oaks, CA: Sage Publications, 1991.

21. Sinha IP, Smyth RL, Williamson PR. Using the Delphi technique to determine which outcomes to measure in clinical trials: recommendations for the future based on a systematic review of existing studies. PLoS Med 2011;8:e1000393.

22. World Bank Group. List of economies. Washington DC, USA, 2017.

23. Browne K. Snowball sampling: using social networks to research non-heterosexual women. Int J Soc Res Methodol 2005;8:47-60.

24. Hsu C, Sandford B. Minimizing non-response in the Delphi process: how to respond to non-response. PARE Online 2007;12.

25. Thomas DR. A general inductive approach for analyzing qualitative evaluation data. Am J Med Eval 2006;27:237-46.

26. Higgins J, Lasserson T, Chandler J, et al. Methodological Expectations of Cochrane Intervention Reviews (MECIR): standards for the conduct and reporting of new Cochrane Intervention Reviews, reporting of protocols and the planning, conduct and reporting of updates. Version 105. Cochrane, 2018.

27. Snilstveit B, Vojtkova M, Bhavsar A, et al. Evidence gap maps: a tool for promoting evidence-informed policy and prioritizing future research. Policy research working paper 6725. Washington DC: Independent Evaluation Group, Public Sector Evaluation Department, The World Bank, 2013: 34.

28. World Health Organization. Framework on integrated people-centred health services. Geneva: WHO, 2018.

29. The Lancet. The NHS at 70 and Alma-Ata at 40. The Lancet 2018;391.

30. van Weel C. Research and clinical practice: how to better answer the needs of patient care. J Clin Epidemiol 2015;68:1244-6.

31. van Weel C, Kassai R. Expanding primary care in South and east Asia. BMJ 2017;356.

32. van Weel C, Kassai R, Qidwai W, et al. Primary healthcare policy implementation in South Asia. BMJ Glob Health 2016;1:e000057.

33. van Weel C, Kassai R, Tsoi GW, et al. Evolving health policy for primary care in the Asia Pacific region. $\mathrm{Br} J$ Gen Pract 2016;66:e451-3.

34. van Weel C, Turnbull D, Ramirez J, et al. Supporting health reform in Mexico: experiences and suggestions from an international primary health care conference. The Annals of Family Medicine 2016;14:279-80.

35. Jünger S, Payne SA, Brine J, et al. Guidance on conducting and reporting Delphi studies (CREDES) in palliative care: recommendations based on a methodological systematic review. Palliat Med 2017;31:684-706. 